BULLETIN Bulletin hispanique

HISPANIQUE Université Michel de Montaigne Bordeaux

118-2 | 2016

Varia

\title{
La versificación de Francisco Álvarez de Velasco y Zorrilla (1647-1704)
}

José Domínguez Caparrós

\section{(2) OpenEdition}

\section{Journals}

Edición electrónica

URL: http://journals.openedition.org/bulletinhispanique/4519

DOI: 10.4000/bulletinhispanique.4519

ISSN: 1775-3821

Editor

Presses universitaires de Bordeaux

Edición impresa

Fecha de publicación: 15 diciembre 2016

Paginación: 493-516

ISBN: 979-10-300-0125-9

ISSN: 0007-4640

Referencia electrónica

José Domínguez Caparrós, «La versificación de Francisco Álvarez de Velasco y Zorrilla (1647-1704) », Bulletin hispanique [En línea], 118-2 | 2016, Publicado el 15 diciembre 2019, consultado el 28 diciembre 2019. URL : http://journals.openedition.org/bulletinhispanique/4519; DOI : 10.4000/

bulletinhispanique.4519 


\title{
La versificación de Francisco Álvarez de Velasco y Zorrilla (1647-1704)
}

\author{
José Domínguez Caparrós \\ UNED - Madrid
}

La description métrique des compositions de ce poète colonial du dernier baroque nous fournit un tableau de la théorie et de la pratique du vers à la fin des siècles d'or. Le commentaire de leurs caractéristiques et de la terminologie métrique prouve le souci d'innovation qui est à l'origine du renouvellement du vers espagnol moderne.

Mots-clés: métrique, versification, baroque, poésie colonial hispanoaméricaine.

La descripción métrica de cada una de las composiciones del poeta colonial del barroco tardío nos proporciona un cuadro de lo que es la teoría y la práctica del verso al final de los siglos de oro. El comentario de sus características y terminología métrica demuestra el afán por innovar que está en el origen de la renovación del moderno verso español.

Palabras clave: métrica, versificación, barroco, poesía colonial hispanoamericana.

The metric description of each of the late Baroque colonial poet's compositions gives us a picture of the theory and practice of verse at the end of the Golden Age. The comment of their features and metric terminology proves the desire of innovation at the origin of the renewal of the modern Spanish verse.

Keywords: metrics, versification, baroque, colonial Spanish poetry.

$\mathrm{E}_{\mathrm{y}}^{1}$

estudio de la versificación del barroco tardío (fines del siglo XVII y principios del XVIII) no ha sido objeto de atención particular, si dejamos aparte el caso de Sor Juana Inés de la Cruz (1651-1695), cuya métrica fue analizada por Tomás Navarro Tomás ${ }^{1}$. Es, sin embargo, un período

1. Tomás Navarro Tomás, Los poetas en sus versos, Barcelona, Ediciones Ariel, 1973, p. 163179.

Bulletin Hispanique, Tome 118, nº 2 - décembre 2016 - p. 493-516. 
interesante, porque el rebuscamiento formal del barroco sigue reflejándose en las formas métricas. El caso del autor al que vamos a dedicar el presente trabajo, el colombiano o neogranadino Francisco Álvarez de Velasco y Zorrilla (1647-1704), tiene el interés de representar lo que sería la actitud de un versificador corriente del periodo, familiarizado con los tratados de Rengifo y de Caramuel, admirador de Quevedo y de Sor Juana Inés de la Cruz, cuya obra llegó a conocer y apreciar. La moderna edición de sus obras, publicadas antes en España en 1703, facilita el corpus de su producción ${ }^{2}$. Si no es un gran poeta, es un versificador normal, consciente de su oficio ${ }^{3}$, lo que tiene el interés de mostrar el ambiente de la época. Ambiente que refleja la vitalidad del artificio, que es, sin duda, una de las fuentes para la renovación de la métrica en la poesía. Construcciones trabajosas que pueden rechazarse como pueriles, pero de las que quien las conozca podrá servirse sutilmente como acicate para la innovación. Este periodo proporciona el caldo de cultivo para que más adelante un Tomás de Iriarte experimente con nuevas formas métricas, o para que el romanticismo disponga de lo necesario para la práctica de la polimetría o use de artificios basados en agudos y esdrújulos simétricamente dispuestos, por ejemplo. Leandro Fernández de Moratín usará del esdrújulo en la construcción de sus versos asclepiadeos. Porque la historia de la métrica no tiene que identificarse con la historia de la poesía representada en el canon de la excelencia estética. Así, al trazar recientemente la historia del endecasílabo dactílico español nos hemos encontrado con dos autores de esta época tardía del barroco americano que, sin estar en la lista de los grandes poetas, hacen una aportación de indudable interés: Pedro de Peralta Barnuevo (1663-1743) y Fray Juan de la Anunciación (1691-1764)

La Rhythmica sacra, moral y laudatoria reúne en un volumen el conjunto de distintos escritos, en prosa y sobre todo en verso, impresos en diferentes lugares y tiempos por distintos impresores. La dedicatoria del libro a D. José Fernández de Velasco y Tobar está fechada en Madrid, a cuatro de diciembre de 1703, y en el prólogo al lector encontramos ya la primera referencia al «ingeniosísimo

2. Francisco Álvarez de Velasco y Zorrilla, Rhythmica sacra, moral y laudatoria, edición y estudios de Ernesto Porras Collantes, presentación de Rafael Torres Quintero, estudio preliminar y notas de Jaime Tello, Bogotá, Publicaciones del Instituto Caro y Cuervo, 1989. En la Biblioteca Nacional de Madrid hay ejemplar de la edición de 1703, así como ejemplares de la edición separada de algunas de las obras que la componen. De ellas, puede verse en línea el texto de: $E l$ Apolo africano, Poema panegírico a Don Gabriel Álvarez de Velasco, su padre, y Elegías decámetras (consulta 30-XI-2012). Marcelino Menéndez Pelayo describe el volumen de la Biblioteca Nacional, con la lista de las composiciones, y se refiere al autor como «innovador en la métrica, versado, no solo en los primores de Rengifo, sino en los primores de la Rythmica [sic] del Obispo Caramuel, a quien más de una vez cita», y como "versificador fácil y abundante, pero contagiado con todos los resabios del mal gusto de su tiempo, que los poetas a lo divino exageraban todavía más que los profanos». Véase M. Menéndez Pelayo, Historia de la poesía hispano-americana, I, edición de Enrique Sánchez Reyes, Madrid, CSIC, 1948, p. 426, n. 1.

3. El verso 5 de un soneto acróstico dice: Inventad en la idea nuevos rigores, p. 61.

4. José Domínguez Caparrós, El moderno endecasílabo dactílico, anapéstico o de gaita gallega, Sevilla, Anejo III de Rhythmica, 2009, p. 57-64. 
Caramuel»y al «doctíssimo Caramuel» (p. 6, 8) , y la proclamación de su voluntad innovadora en algunos aspectos de la métrica, «y assí -dice- me atreví a fábricas nuevas de metros, y a otras varias invenciones, nunca de mí vistas, ni aprendidas de otro», señalando las composiciones en eneámetros (decasílabos) con esdrújulos al principio y al final de verso. Nueva composición que se diferencia de la de Sor Juana Inés también en eneámetros (decasílabos) con esdrújulo solo al principio de verso ${ }^{6}$. Otros artificios destacados en su obra por el autor:

No siendo de menos violencia, y dificultad para mí los laberintos de las Cruzes, que yo compuse en su [de Sor Juana Inés] obsequio, los Acrósticos, y Paranomasias; y principalmente el Soneto a los dos libros suyos, en que encontré tales espinas, que no me atreviera oy a empeñarme a hacer otro del Arte; cuya disgressión no he podido escusar; porque si por baxos despreciares los versos de este libro, les hagas algún agasajo por el mérito que tiene en su trabajo, como también lo reconocerás en otras nuevas inventivas de varios metros, y composiciones, que tengo en otras obras Cómicas, que por algunos motivos las retiro por aora de la Imprenta (p. 10).

Si de algo se siente seguro el autor es del mérito del trabajo de la forma métrica, pues llega a decir que tiene sin publicar composiciones en formas métricas de su invención.

I. En 1703 se imprime en Burgos el primer conjunto de poemas, que se titula Elegias decámetras a los Dolores de la Virgen Santíssima, ajustadas a distintos centones de Virgilio. Francisco Álvarez de Velasco sigue a Caramuel en la denominación de los versos; cuenta las sílabas métricas hasta el último acento, cuyo número determina la calificación del mismo: eneámetro, acento en la novena, es el decasilabo; decámetro, acento en la décima, es el endecasilabo. Dejando aparte unos versos latinos dedicados por Joseph Gerónimo de Sousa con acróstico de la letra inicial (ÁLVAREZ) y final (VIRGILIO), explica en la advertencia el autor su propósito: narrar los dolores de la Virgen apoyándose en la cita de dos o tres versos de Virgilio, que siguen a cada uno de los cuartetos endecasílabos (A B B A $)^{7}$. En la advertencia califica de quartetas Decámetras estas combinaciones, y

5. Para evitar la repetición del título en cada referencia, debe entenderse que el número de la página entre paréntesis se refiere a la edición de 1989 de la obra de Álvarez de Velasco, ya citada. En los textos citados de Álvarez de Velasco, se señala con tilde el acento según las normas ortográficas modernas.

6. Innovación señalada por Ioseph Vicens en sus adiciones a Rengifo en 1703. Véase Juan Díaz Rengifo, Arte poética española, aumentada en esta última impresión, Barcelona, Imprenta de María Ángela Martí, sin año [1759], p. 65: «Notese, que inventó la Americana Poesia Musa Decima un singular Romance de diez sylabas, cuyos primeros vocablos son Esdruxulos, como:

Lamina sirva el Cielo al Retrato,
Lisida de su angelica forma;
Calamos forma el Sol de sus luces:

7. El sistema de notación de la estructura métrica es el siguiente: la cifra numérica se refiere al número de sílabas de los versos que siguen; la letra mayúscula (para versos de más de ocho sílabas) o minúscula (para versos de ocho sílabas o menos) señala los versos que riman (en consonante, y, 
nos da otra información referida a la métrica: los consonantes agudos no sirven para «la composición de arte mayor». Nótese que arte mayor se refiere al verso endecasílabo, no al arte mayor del siglo XV representado por el verso de Juan de Mena ${ }^{8}$. Así es como hoy se usa el concepto de arte mayor para calificar todo verso de más de ocho sílabas. Antes de los 81 cuartetos del conjunto (p. 22-54), hay un soneto en agudos (á, é, í, ó), que parece contradecir la afirmación anterior sobre la inadecuación de los agudos al endecasílabo. Por lo demás, esta forma de soneto agudo era propia de la poseía burlesca del siglo XVII. El remate del conjunto es un madrigal de 28 versos (p. 54-55), endecasílabos y heptasílabos, rimados en consonante todos a modo de silva, que incorpora igualmente versos latinos de Virgilio en distintos lugares, en mezcla típicamente barroca de dos lenguas 9 . Sin entrar en todos los detalles de la prosodia, hay que destacar la acusada tendencia de Francisco Álvarez de Velasco a la sinéresis, en palabras como vivía, caída, reos, mío, deseo, caos, negreando, etc. ${ }^{10}$. Otra característica de la métrica del neogranadino es el seseo en la rima consonante: instancias / ansias (p. 23 y 47), Ocaso / regaço (p. 46).

Sigue la composición de la que se mostraba tan orgulloso en la advertencia, "A los Dolores de la Virgen", Romance eneámetro, que empieçan, y acaban todos los pies con esdrújulos (p. 56-59). Los 48 decasílabos, divididos en grupos de cuatro, van constantemente acentuados en $1 .{ }^{\mathrm{a}}, 6 .^{\mathrm{a}}$ y $9 .^{\mathrm{a}}$ sílabas, y la asonancia esdrújula en áia se reduce a $a ́ a$ - $a$ (sílabas tónica y final) en pocas ocasiones: ásperas, tártaras, cláusulas, lámparas. El artificio queda perfectamente marcado en la representación gráfica de cada una de las 12 estrofas, numeradas, de que se compone. Véase como ejemplo la primera de ellas:
Ánimo
Coraçón, y si Tímido
Prófugo
En tus lágrimas Pávidas
Náufrago
Oy presumes Atónito
Únicas
Tus congoxas Fantásticas ${ }^{11}$

cuando así se indica, en asonante). El signo - (guion medio) indica la falta de rima en el verso; y el acento tras la letra (por ejemplo, a' B') significa que la rima es aguda.

8. El Diccionario de Autoridades (s. v. arte) nos da un testimonio de la ambigüedad del término versos de arte mayor: «Se llamaban assí los que antiguamente se hacían, que constaban de doce sylabas: como las coplas de Juan de Mena, el Cartujano y otros. Algunos modernos confunden el verso de arte mayor, llamando assí al que consta de once sylabas, cuyo proprio nombre es Verso hendecasylabo.» Claro que el mismo diccionario ilustra el uso censurado cuando define el soneto: "Composición métrica de catorce versos de arte mayor, todos consonantes."

9. A Caramuel se debe la caracterización métrica del madrigal como forma que, por tener veinte versos como máximo, se distingue de la silva, y que, por no estar dividida en estrofas, se diferencia de la canción. Véase Juan Caramuel, Rítmica, Tomo II, edición y estudio preliminar de Isabel Paraíso, traducción de Avelina Carrera, José Antonio Izquierdo y Carmen Lozano, Valladolid, Universidad, 2007, p. 312. La edición latina de esta obra es de 1665.

10. Especialmente llamativa es la escansión de la palabra agonía como trisílaba, pero que mantiene la consonancia en ia con la palabra pía. Es el caso del verso Ni esta les falte la tímida agonia, endecasílabo además dactílico, que rima con el primero del cuarteto: O Santíssima Esposa, escucha pía (p. 23).

11. Versos citados por Emilio Carilla en su estudio sobre el verso esdrújulo en América, donde destaca además el uso de este tipo de verso por Álvarez de Velasco, cuando dice: «A todos 
Viene a continuación un «Soneto Acróstico, en que de los principios dél se van formando las palabras: Quasi Cypressus in Monte Sion, quasi myrrha electa dedi suavitatem odoris (p. 60-61). El acróstico se forma con una o más sílabas del principio de cada verso. Consuenan fragancia / ansia, con seseo.

Sigue un madrigal de 30 versos, dedicado también a los dolores de la Virgen, en endecasílabos y heptasílabos consonantes, con muchos pareados. Vemos que Álvarez de Velasco se extiende algo más de los veinte versos que Caramuel asignaba al madrigal.

Al descendimiento de Cristo y a los dolores de la Virgen está dedicado el romance octosílabo que sigue, asonante en $o e$, dividido en cuartetas, compuesto de 216 versos (p. 64-71).

La Salve para cantar a Nuestra Señora de la Tristeza, que sigue (p. 72-74), es una composición original, toda en versos esdrújulos. Empieza con un estribillo, compuesto de 16 versos, silábicamente irregulares $(7+6,6+6,7,11,5+5,5)$, con sobreabundancia de esdrújulos, no solo en todos los finales de verso, sino también en interior. Hay repetición de versos formados todos con las mismas palabras esdrújulas en distinto orden (yámbicos, júbilos, métricos, cánticos). A este estribillo sigue un grupo de 7 cuartetas octosílabas esdrújulas con asonante $a-a$ en todos los versos pares, y uno o dos versos del texto latino de la Salve al final de cada cuarteta.

A continuación hay un largo romance de 264 octosílabos, asonante en uo, que, como de costumbre, se representa dividido en cuartetas (p.75-83). Salvo la asonancia de la palabra descuydo en uo (v.254), no tiene ninguna otra peculiaridad métrica especialmente reseñable. El tema es el del pecador agonizante que busca refugio en la Cruz.

Mayor originalidad tiene la composición siguiente: «Cláusulas de la Salve glossadas, en dézimas» (p. 84-94) $)^{12}$. La forman 32 décimas en octosílabos con el esquema de rima $a b b a . a c c d d e$, seguida de un quebrado (de entre $4 \mathrm{y}$ 7 sílabas) que rima con el último verso [rima $e$ ]. El quebrado corresponde a un fragmento del texto de la Salve glosado (Sálvete Dios; Reyna y Madre; De Misericordia; Vida, y Dulçura; Esperança nuestra; etc.). Un tipo de décima con el mismo esquema y la adición de un verso que rima con el último es el de las diez décimas satíricas de Góngora que empiezan Ya de mi dulce instrumento, aunque

deja atrás en el ejercicio de enhebrar esdrújulos un santafereño devoto de Quevedo y Sor Juana Inés de la Cruz: me refiero al capitán Álvarez de Velasco y Zorrilla.»Y añade que «no desdeñó ninguno de los primores métricos en lo que a esdrújulos se refiere. Álvarez de Velasco no solo se propone imitar a Sor Juana sino también superarla en novedades espectaculares; al esdrújulo inicial, al final, característicos de numerosos versos cultistas, los acumula de tal forma que el verso se estrangula y respira apenas en alguna sílaba intermedia». Véase E. Carilla, «El verso esdrújulo en América», Filología, I, 1949, p. 169-170. Zamir Bechara dice de Álvarez de Velasco que «cultiva sistemáticamente, más que ningún otro poeta, el verso esdrújulo en la Nueva España»; y pasa revista a las características de dicho verso en sus distintas composiciones. Véase Zamir Bechara, "La moda de los sdruccioli en España y en el nuevo reino de Granada», Thesaurus, tomo L, núm. 1, 2 y 3, 1995, p. 427-436.

12. La preferencia de las décimas octosílabas como estrofa de las glosas es señalada por Caramuel, op. cit., p. 341. 
la adición en este caso es la del mismo verso octosílabo y digan [o diga] que yo lo digo, como estribillo. Una estrofa semejante emplea también Francisco Álvarez de Velasco, como veremos más tarde (p. 401-402).

El mismo procedimiento es usado en la composición que sigue: "Cláusulas del Ave María, glossadas en dézimas con discursos» (p. 95-101). Las 16 estrofas, con la misma estructura de las de la glosa anterior, están acompañadas de un comentario en prosa que rodea al texto en verso; forma normal de presentar los comentarios humanistas. Métricamente cabe señalar el seseo en rimas como luz / Jesús, voz / Dios.

De 478 endecasílabos y heptasílabos se compone el largo poema titulado «A las agonías del Huerto. Idilios» (p. 102-115), con rima consonante y estructura de silva.

II. El 19 de marzo de 1703, en Burgos, es la fecha de la aprobación del P. Juan Pablo de Aperregui a un grupo de poemas dedicados a los novísimos (muerte, juicio, infierno y gloria). El mismo jesuita dedica un soneto y dos octavas a esta obra de Francisco Álvarez de Velasco. El conjunto dedicado a los novísimos está formado por 2994 versos, divididos en cinco composiciones, cada una de ellas precedida por una ilustración que alude al tema.

La primera es una silva de 217 versos, endecasílabos y heptasílabos con rima consonante, titulada «Moribundo, que naufraga, desamparado de todo humano consuelo, en las borrascas de las últimas agonías, en la metáfora de un Navegante» (p. 120-126). El recuerdo del gongorino náufrago de las Soledades parece inevitable, si bien el estilo no tiene nada que ver con el del cordobés.

Sigue la composición dedicada al primero de los novísimos, la muerte: «Novíssimo de la muerte, en que habla con Dios un agonizante» (p. 128-148). Se trata de un romance octosílabo asonante en ae con 12 sonetos intercalados en el conjunto del romance. De estos, cuatro (p. 132-134, 145, 147-148) tienen rima consonante aguda, aunque no se trata de sonetos burlescos. Es muy visible el seseo en la rima aguda del último de los citados: Dios, atroz, feroz, vos; feliz, salis; Cruz, luz, Jesús. Y en cuanto a la rima asonante, se atestigua la equivalencia de $i$ a $e$, en sílaba final átona; en la serie de asonancia en ae se encuentran las palabras fácil, frágil, áspid. Toda la composición comprende 656 versos.

$\mathrm{El}$ "Novíssimo del juizio, insinuado en la consideración de una metáfora» (p. 150-159) lleva la calificación métrica de canciones reales. Se trata de veinte estancias de canción italiana, de catorce versos endecasílabos y heptasílabos, con la estructura de rima consonante siguiente: $A B C A B C c d d E E D F F$. El número total de versos es 280 .

El «Novíssimo del infierno», calificado de sylva, consta de 1238 versos en la silva, más un soneto final, 1252 versos en total (p. 161-196).

También es una silva de 589 versos el «Novíssimo de la gloria», calificado de bymno (p. 198-214).

Sigue la traducción de unos versos latinos en cuatro pareados endecasílabos (p. 215) a los que se les añade el texto latino, que suena como un endecasílabo, con acentos en 2. a, $6 .^{a}$ y $10 a^{a}$ : erravimus a via veritatis, tomado de la Biblia Vulgata (Sapientia, 5, 6). 
Una «Definición de la vida, que solo pueden sus mismas propensiones ser embeleso, salsa, o hechizo, para poder passarla» es calificada de sylva y consta de 97 versos endecasílabos y heptasílabos, con rima consonante (p. 216-218).

Sigue un romance endecasylavo titulado "A honra, y gloria de la Beatíssima Trinidad, y de la Inmaculada Virgen María», con 44 endecasílabos asonantes en $o a$. Nótese que Francisco Álvarez de Velasco habla ahora de endecasílabo y no de decámetro, según la nomenclatura de Caramuel que había utilizado al principio, como vimos. El texto se divide gráficamente en cuartetos (p. 219221). Recuérdese también que el romance endecasílabo era una forma reciente, de la segunda mitad del siglo XVII, según T. Navarro Tomás ${ }^{13}$.

Viene a continuación una serie de 25 sonetos (p. 222- 247) dedicados a distintos santos o a temas de carácter ético. Los tercetos riman C D C D C D en todos los casos, menos en dos que riman C D E C D E. No escasean los ejemplos de seseo en la rima: hermosa / goza / lossa; naces / frasses; Teresa / fineza, etc.

El largo poema titulado "Sermón eneuclástico estoyco sobre la doctrina de Epiteto, de que solo se debe cuidar lo que está en mi propio alvedrío» (p. 248-265) tiene 534 versos, endecasílabos y heptasílabos, organizados en cinco canciones u odas pindáricas, que ocupan la mitad del poema (267 versos), seguidas de tres silvas, de 48, 30 y 189 versos respectivamente (267 versos). Francisco Álvarez de Velasco, que no emplea el término de canción u oda pindárica, sigue el esquema establecido por Francisco de Quevedo en su Elogio al Duque de Lerma don Francisco (BAE, LXIX, p. 12), con una estropha o estrophe (rima consonante: $a B A B c c D e E D F G g f H H$ ), una antistrophe con el mismo esquema de la estrofa, y un epodo (rima consonante: $A B$ a $b$ a $C C$ $D D$ e E F G G F h I H i J J). El esquema, en la composición del neogranadino, presenta las siguientes variaciones: 1) falta $f$ en la tercera estrofa; 2) la cuarta estrofa y antistrofa tienen $D e D E$ en lugar de $D e E D$; 3) la quinta estrofa, como la cuarta, $D e D E$; 4) la quinta antistrofa suprime $G$, añade un cuarteto, y el final es $H I i h J J ; 5)$ el quinto epodo tiene $h I I h$ en vez de $h I H i$.

Los Suspiros de San Agustín (p. 265-273) son un conjunto de cuatro silvas de endecasílabos y heptasílabos. El suspiro I, para antes de la confesión, consta de 72 versos; el II, para antes de la misa, tiene 35 versos; el III, para la acción de gracias, 25; y el último, traducción de una oración de San Agustín -traducida también por Sor Juana Inés de la Cruz en 13 redondillas octosílabas, abba-, consta de 47 versos.

Dos villancicos dedicados a San Agustín vienen a continuación, interesantes por su polimetría e irregularidad silábica en algunos momentos. El primero de ellos (p. 273-275), de 88 versos, los tiene de distinto número de sílabas: tetrasílabos, pentasílabos, hexasílabos, heptasílabos, octosílabos y alguno compuesto de dos heptasílabos. Parecen percibirse en algunos momentos en que se combinan el octosílabo y su quebrado los fenómenos de la sinalefa y la compensación entre versos. Por ejemplo: Pues si esse rayos blasona, / Esta

13. Tomás Navarro Tomás, Métrica española, Madrid, Ediciones Guadarrama, 1972, tercera edición corregida y aumentada, p. 259. 
sazona (vv. 17-18); No menos que a la luz debe, / En las que bebe, / El ver ya sin confusión / A esta sazón (vv. 25-28); y algún caso más.

El segundo villancico (p. 276-277) consta de 49 versos, con un comienzo de 11 versos irregulares $(6+5,7+5,6,5,11,11,6,6,6,11,6+6)$, con mezcla de rima consonante y asonante, en los que se percibe una base de seguidilla. Sigue un grupo de 32 octosílabos, con los pares asonantes en ó; y termina con un grupo de seis endecasílabos arromanzados en $o ́$ también. Es llamativo un octosílabo con dos sinéresis como el siguiente: Hazia en este dia las fiestas (p. 277). Como puede apreciarse, la estructura de estos llamados villancicos no tiene que ver con la de la forma de estructura fija medieval (cabeza, mudanzas y vuelta). El primero de los comentados, en el que intervienen cuatro coros, tiene una estructura más compleja que el segundo.

La silva dedicada "A San Gerónimo en el desierto» consta de 107 versos endecasílabos y heptasílabos con rima consonante (p. 277-280).

De lyras califica el poema "A la conversión, y llanto de Santa María Magdalena» (p. 280-283), que es una canción italiana compuesta de cuatro estancias con el esquema siguiente: $a b A B C D c d E E F F G G H H$; y un remate de cuatro versos, $A$ a $B B$, reconocible además porque el poeta se dirige a la canción (Mas Canción, baste; baste, afecto mio, v. 64). En la segunda estancia falta $d$, y tiene 67 versos en total la composición.

Forma de silva tiene el poema de 88 versos "Al felicíssimo, y mejor ladrón, San Dimas» (p. 283-285), subtitulado ilidion.

Sigue una "Glossa, o troba del Laudate pueri Dominum, para cantar en la Escuela de Christo» (p. 286-289), especie de liras arromanzadas; se compone de 12 estrofas de cinco versos endecasílabos y heptasílabos, 7 - $a-11 \mathrm{~A} \mathrm{~A}$; la rima es asonante en ea en todo el poema, y como quinto verso del grupo se repite siempre el mismo, Alabad a Dios, Niños, en su Escuela; después de cada estrofa hay un texto latino de carácter religioso.

El mismo tipo de estrofa es el empleado en la composición que viene a continuación y que se titula «El remedio de un alma afligida solo es, no cansarse de clamar a su Pastor Jesús, en la metáfora de una Ovejilla» (p. 289-291). Las trece estrofas, con repetición del quinto verso (Bala, que esse balar te da la vida), son calificadas de endechas, tienen la misma asonancia en $i a$, en los versos pares, y van precedidas de un estrivillo con la siguiente forma: $7 a 5 a$ (asonante $i a$ ), $8 b b$ (consonante or), $8 c c$ (consonante era), $8 d 11 D$ (consonante $i d a$ ). El verso $11 D$ del estribillo es el que se repite al final de cada estrofa.

«Desengaño que ofrece la soledad» es el título del romance de 56 octosílabos, divididos en cuartetas, con asonancia aguda en $u$, que viene a continuación (p. 292-294).

El romance asonante en $o$ formado por 84 octosílabos divididos en cuartetas que sigue tiene el título de «Soliloquio, en que contrapesa el alma su ser de nada, con el sublime de Dios» (p. 294-297). Empieza con un estrivillo, que se repite después de cada una de las cuartetas y que dice: Ay mi Dios, y mi Señor! I Quién sois vos, y quién soy yo? 
Llama sextilla a la combinación de octosílabos que riman en consonante, $a b$ $a b a b$, única estrofa del poema titulado «Breve arte para llegar desde pecador a justo» (p. 298).

La "Oración de un enfermo sobre el Cántico del Santo Rey Ezechías» (p. 298-300) se compone de 15 estrofas con el esquema 7 - $a$ - 11A, con rima asonante en $e e$ en toda la composición. Al margen de cada estrofa figura en latín el texto bíblico correspondiente.

Llama dísticos a los 22 endecasílabos pareados del poema "A un hipocóndrico» (p. 300-301), donde podemos leer la consonancia con seseo prisa / atiza.

Pareados son también los 20 versos del poema titulado «Lo que passa en los aplausos del mundo» (p. 301-302), pero los versos son endecasílabos y algunos heptasílabos.

La "Glossa en esdrújulos al engaño de los gustos temporales» (p. 302-303) empieza con el texto de una cuarteta octosílaba esdrújula con rima asonante en los pares que es glosada en cuatro décimas octosílabas con rima consonante esdrújula, $a b b a a c c d d c$; según la forma más frecuente y tradicional de la glosa, el último verso de cada décima repite el texto del correspondiente verso de la copla glosada.

Califica de sylva la composición de 133 endecasílabos y heptasílabos con rima consonante dedicada a alabar el libro del P. M. Fray Alonso de Zamora sobre historia de la orden de Predicadores en su provincia del Nuevo Reino (p. 304-307). Lleva notas marginales de tipo erudito.

A los ocho cuartetos endecasílabos, $A B B A$, consonantes, los llama redondillas de arte mayor. Forman el poema titulado "A Lelio, sentencias metafóricas y morales» (p. 308-313), que se construye a base de que cada verso reproduce el primero de un soneto distinto de Quevedo, cuya referencia se da junto al texto. De travesura califica este artificio, cuya dificultad pondera "porque son muy pocos los pies que tienen consonante con otro, como porque siendo a tan distintos assumptos, y los más péndulos, apenas se halla alguno, que pueda travar con otro algún sentido" (p. 308). Nótese la terminología métrica: redondilla, estrofa de cuatro versos; arte mayor, verso largo.

Sigue un grupo de quince sonetos, de tema predominantemente ético, entre los que cabe destacar un soneto en esdrújulos (p. 321), dos formados con versos de Quevedo (p. 322-325), otro en esdrújulos (p. 326), y uno «en consonantes inusitados, que cada uno sea lugar de la Sagrada Escritura» (p. 330-332), donde riman las palabras siguientes: Acab, Nabot, Lot, Rab; Moab, Nembrot, Ephot, Ioab; Baruc, Doeg, Abid; Habacuc, Cileg, David. En notas marginales explica lo referido a estos nombres ${ }^{14}$.

14. Véase Antonio Alatorre, Cuatro ensayos sobre arte poética, México, El Colegio de México, 2007, p. 321-330, donde traza la historia de algunos ejemplos de sonetos con nombres bíblicos agudos desde el primero de Lope de Vega, en su comedia Los locos por el cielo (1600), quien escribió algunos más del mismo tipo, hasta los ejemplos de poetas coloniales, incluyendo el de Francisco Álvarez de Velasco, pasando por Góngora o Calderón. 
De ovillejos es calificada la composición de trece versos, endecasílabos (9) y heptasílabos (4), que consuenan $a B$ a $B C C d D c E E F F$ y que son la traducción, comentario, de un dístico latino sobre la melancolía. Hay que notar la consonancia con seseo mesa / tristeza (p. 333).

Con el pomposo título de «Sonora música a la Puríssima Concepción de la Virgen, quien por Madre de Dios lleva el punto más alto, cuyo assumpto se explica en los términos músicos de $M i$, Sol, y $L a$, en la glossa de truncados siguiente» (p. 334-335), una cuarteta octosílaba aguda con asonancia en $o ́$ en los versos pares es glosada en cuatro décimas octosílabas $a b b a$. $a c c d d c$ cuyo último verso repite el correspondiente de la cuarteta y en donde abundan las terminaciones agudas, terminación a la que se refiere el adjetivo truncados aplicado en el título a los versos.

La composición «A la Milagrosa Imagen de Nuestra Señora de Chiquinquirá, QUINTILLAS» (p. 336-339) consta de 24 estrofas de octosílabos consonantes $a b a a b$.

Métricamente interesante es la composición siguiente (p. 340-344), «Mysterios del Rosario, que se cantan en la Ciudad de Santa Fee», con un EMPIEZO de versos de distintas medidas, en la siguiente organización: Coro 1, 10A 11A 11B 11B; Coro 2, 10 - 4c 11C; Coro 1, 4d 11D; Coro 2, 4d 11D. $7 \mathrm{e} 10 \mathrm{E} 11 \mathrm{~F} 11 \mathrm{~F}$. Los decasílabos van acentuados en tercera, sexta y novena sílabas, y entre los endecasílabos hay cuatro con ritmo dactílico. Siguen dos versos de introducción a los misterios gloriosos (11A 11A) y cinco estrofas (una por cada uno de los misterios), con el esquema $6 \mathrm{a} \mathrm{a} \mathrm{b} \mathrm{b} 11 \mathrm{C} \mathrm{C}$, con rima consonante. La introducción a los misterios gozosos, tras la repetición de las dos primeras intervenciones de los coros en el EMPIEZO, consta de dos endecasílabos consonantes (11A 11A), y siguen cinco estrofas de cuatro versos con la misma rima asonante en eo en todas ellas $(8-\mathrm{a}-11 \mathrm{~A})$. Los misterios dolorosos, tras la reproducción de parte del EMPIEZO, y la introducción de dos endecasílabos consonantes (11A 11A), constan de cinco estrofas de cuatro versos heptasílabos y endecasílabos con la misma asonancia en eo en todos los pares de todas ellas (7 - a - 11A). Los dolorosos se diferencian de los gozosos solamente en el uso de heptasílabo en lugar de octosílabo. Termina con la repetición de parte del EMPIEZO. Son notas destacables de esta composición: la polimetría, con matices de irregularidad en el comienzo, la mezcla de rima consonante y asonante, la fuerte presencia del ritmo acentual ternario (dactílico y anapéstico), ligado a la música y que anuncia la consagración de ritmos acentuales muy marcados en la poesía culta del romanticismo, por ejemplo en el decasílabo anapéstico o de himno (acentuado en 3. ${ }^{\mathrm{a}}, 6 .^{\mathrm{a}}$ y $9 .^{\mathrm{a}}$ ).

El «Villancico al Nacimiento de Christo Señor Nuestro, para la Noche Buena» (p. 345-346) empieza con un estrivillo de siete versos, hexasílabos y un endecasílabo (6 a b a b - b 11B), con rima asonante, y sigue con un romance de 44 octosílabos asonantes en $e a$.

Esta misma asonancia es la del romance, de 44 octosílabos también, que sigue: «Al mismo Nacimiento de Christo» (p. 347-348). 
Sobre el mismo tema, "Otro villancico al mismo Nacimiento de Christo S. Nuestro" (p. 349-352) consta de 96 versos, con un primer grupo de 10 al principio, que funcionan como estribillo irregular (8 - a - a; 10- 6a; 12A 6a; $12 \mathrm{~B} 7 \mathrm{~b}$; rima asonante), y un romance octosílabo asonante en eo (la misma asonancia $a$ del estribillo), dividido en cuartetas. Es reseñable la equivalencia de $u$ en sílaba átona final a $o$, en la asonancia, pues asuenan en $e o$ las palabras latinas genuflectetur, eius, coelestium, Deum.

El villancico titulado «A la Concepción de la Virgen Santíssima» (p. 353-355) se construye con un cuerpo de seis cuartetas arromanzadas en $e o$ (asonancia de todo el poema) (vv. 33-56), precedidas y seguidas de polimetría hasta los 64 versos del conjunto. Versos de $8 ; 5$ y 7; 10 y $6 ; 12$ y 6 sílabas se encuentran en estos pasajes, pero la rima siempre es asonante en eo. Hay mezcla de diálogo en latín.

En el título de la siguiente composición se definen las características métricas de la forma usada: «Al Nacimiento de Christo Villancico, y Ensalada, que es un género de versos, y composición, que no va atado a precisos consonantes» (p. 356-359). El esquema es: $9 \mathrm{~A} 12 \mathrm{~A} 8 \mathrm{~b} \mathrm{~b} \mathrm{c} \mathrm{c} \mathrm{a} 9 A$ d e e f d f e a g $9 A 12 \mathrm{H}$ $8 \mathrm{~g} \mathrm{~h} \mathrm{i} \mathrm{j} \mathrm{j} \mathrm{i} \mathrm{k} 11 \mathrm{k} \ldots$ y todos los siguientes son octosílabos consonantes sin orden rígido hasta completar el conjunto de 114 versos. Hay que notar, en la edición que vemos, la representación de algunos octosílabos divididos en líneas distintas (v. 95: 1. No es tal. / 2. Ni Adonis tampoco?; v. 106: 2. Los mismo es. I 1. No es tal. / 2. Sí es tal; v. 108: en el blanco. / 1. Por aí sì). El metro y la rima indican como defectuosa tal fragmentación.

III. El siguiente conjunto de poemas lleva el título de Vida y milagros de nuestro taumaturgo y apóstol de las Indias, S. Francisco Xavier. Empieza con un poema titulado "Quintillas", que comprende 57 estrofas de octosílabos consonantes a $b a a b$, con un total de 285 versos (p. 363-370).

La «Vida y charidad del gran Patriarca de Alexandría San Juan Limosnero» (p. 371-376) es el título del poema que sigue y que se califica también de quintillas. Son 41 las estrofas de que se compone, todas ellas de versos octosílabos que consuenan $a b a$ a $b$. No faltan ejemplos de seseo en la consonancia (veloz / Dios, sagaz/mas).

El cuarteto lira asonantado con el esquema $7-a-11 A$ es la estrofa empleada en el poema titulado «Sobre aquel verso del psalmo Defesit narraberunt mibi in qui fabulationes, sed non vt lex tua; y las del Evangelio, quid prodest homini, etc.» (p. 377-380). Los 29 cuartetos van precedidos de dos versos 7 a $11 A$ que se repiten a modo de estribillo en muchos lugares del poema y cuya asonancia en ia es la misma de toda la composición.

Un romance de 88 octosílabos asonantes en ia es la composición siguiente (p. 381-384), que va precedida de una larga introducción en prosa sobre «Tres qualidades singulares que tiene el Oro se hallan solo en la ceniza...».

Otro romance de 132 octosílabos asonantes en ea es la forma del poema titulado "Interés y utilidades de la Paciencia. In pacientia vestra possidebitis animas vestras ( ( . 385-388). 
Llama dézimas a la composición titulada «Amante, que con la acelerada muerte de Nise restaura la razón, que le tenía usurpada la tyranía de su amor» (p. 389-391), dedicada a Sor Juana cuando se enteró de su muerte varios años después en Madrid. Las ocho estrofas tienen el esquema de la espinela $8 a b b a$ $a c c d d c$, y encontramos rima con seseo (belleza, empieza, pavesa).

Sigue un soneto "A don Juan Andrés Oliniani» (p. 392-393), precedido de una larga explicación sobre las circunstancias del mismo, incluyendo una larga cita en latín. Los tercetos riman CDC. DCD.

«Buelve a su quinta Anfriso solo, y viudo» (p. 394-398) se titula la siguiente composición, que empieza con un grupo de ocho versos bajo el nombre de elexias, con el siguiente esquema: $7-a-a 8-a-11 A$, donde la rima es asonante en $i a$. Sigue, bajo el nombre de endechas, con 32 estrofas del tipo 7 $a-11 A$, con la misma asonancia en $i a$; y al final se repiten los ocho primeros versos cambiando levemente el texto del último endecasílabo.

Apóstrophe llama al poema titulado «Contra la común opinión que siguió la Gentilidad...en las injustas alabanzas de Lucrecia...» (p. 399-400), que consta de 22 versos endecasílabos y heptasílabos, consonantes todos, frecuentemente pareados.

Original es la combinación de una cuarteta y una septilla, formando una undécima u oncena, del poema «El derecho y las leyes han de ser derechas en quanto el hombre lo puede ser» (p. 401-402). La combinación de la rima consonante es: $8 a b b a . a c c d d e 10 \mathrm{E}$; y es una modificación de la espinela, en la que se sustituye el último verso por un pareado: $10 \mathrm{E}$ es el mismo verso repetido (que por esto el Derecho es derecho) a modo de estribillo. El total de 55 versos lo forman cinco estrofas de este tipo. Antes (p. 84-94) hemos visto un ejemplo semejante donde se califica de décimas a las estrofas.

Un obillejo es la unión de 26 endecasílabos y heptasílabos, todos con rima consonante y con frecuentes pareados, en el poema titulado «A Pilatos, y en él a los juezes...» (p. 403-404).

«A la professión y velo de la Señora Doña María-Ana de Valençuela Faxardo..." (p. 405-406) consta de un estrivillo de nueve versos de distinta medida: $12(6+6)-A^{\prime}-6$ - - 11 A' 6 a' a' ; y siguen siete quintillas con uno de los esquemas: $8 a b a a b, 8 a b a b a$. Seseo en la rima: aprecie / Ecclesiae, rapaz/ jamás.

«Letra para cantar un domingo...» (p. 407-409) tiene cuatro estrofas iniciales, correspondiente cada una de ellas a la intervención de un coro, con el siguiente esquema la primera $12 A^{\prime} 11 B^{\prime} 6 b^{\prime} a^{\prime} 12 A^{\prime} A^{\prime}$ (consonante aguda or, er); las tres siguientes tienen el esquema $6-a^{\prime}-a^{\prime} 12 A^{\prime}\left(12 A^{\prime}\right.$ es un verso repetido). Bajo el título de coplas, las estrofas siguientes, en número de quince, tienen el esquema $8-a^{\prime}-11 A^{\prime}$ (con la misma asonancia aguda en $o$ ). Nótese la mezcla de rima consonante (primera estrofa) y asonante (el resto del poema).

El siguiente poema, titulado "Otra letra» (p. 410-412) empieza con un estrivillo en prosa (Niños a la Escuela, a la Escuela Niños, a la Escuela de Christo vengan a leer, que en ella el amor es el Maestro que enseña a leer sin açotes, y más a comer). Las once estrofas siguientes, bajo el título de METRO, tienen 
el esquema $6-a^{\prime}-a^{\prime} 8-a^{\prime}$ (la misma rima asonante aguda en $e$ en todo el poema). Son destacables los finales de algunos versos en palabras vacías: que, pues, aunque.

Sigue una serie de once sonetos de carácter religioso y ético, a veces con aclaraciones iniciales (p. 413-424), entre los que cabe destacar el primero, "Soneto en agudos», donde consuenan con seseo veloz, feroz, Dios. Los tercetos riman $C D C$. $D C D$ siempre menos en una ocasión, en que riman $C D E$. $C D E$.

Los 66 versos de la composición «Al M. R. P. M. Fr. Pedro de Tobar y Buendía,...» (p. 425-427), calificada de madrigal, son endecasílabos y heptasílabos (9) que riman en consonante y alguno queda suelto (por ejemplo, los versos 6, 20, 46, 47).

Dos dézimas forman el poema precedido de una introducción en prosa, «Aunque María Santíssima desde el primer instante...» (p. 428): 8 a b b a $a c c$ $d d c$, con mezcla de rima consonante llana y aguda.

La traducción de dos versos latinos, que sigue (p. 429), tiene el esquema $8-a-a$ (asonante en $i a)$.

Las «Reconvenciones tiernas,...» (p.430-433) empiezan con una estrofa de esquema 8 a $11 A B^{\prime} 8 b^{\prime}$ (con rima consonante en ido y en é), seguida de 16 estrofas con el esquema $7-a-11 A$ y la misma asonancia en io. En algunos momentos (tras las estrofas numeradas VIII, XIII, XV, XVI y XVII) se repite la primera, y todas ellas llevan al margen un texto en latín.

Sigue el poema titulado «La Sequencia del Santíssimo Sacramento en esdrújulos» (p. 434-438), romance con asonancia ao en los pares y todos los versos esdrújulos, dividido en 35 cuartetas, cada una con texto latino al margen.

Viene luego una serie de composiciones dedicadas a Santa Bárbara. La primera es un soneto muy artificioso, como se explica en el mismo título: «Soneto a la Gloriosa Virgen, y Mártir Santa Bárbara, Abogada en las tempestades, y a quien le ofreció Dios conceder por su intercessión a sus devotos, el que no mueran sin los santos Sacramentos, a cuyo assumpto habla este Soneto, sino [sic] elegante, trabajoso, por formar de las primeras, y segundas dicciones, leídas azia abaxo, un Hymno a la Santa, que dize lo mismo en Latín, que en Romance» (p. 439). Leyendo hacia abajo la primera palabra de cada verso se forman seis heptasílabos que consuenan $a a b-b b$; y con las segundas, otros seis heptasílabos con la consonancia - - $a a a-$, y palabras que tienen significado en latín y español. Ya Rengifo trató de los sonetos en dos lenguas.

Continúa la serie con otro soneto a Santa Bárbara (p. 440) con los tercetos que riman CDC. DCD, como lo hace casi siempre.

Sigue con «Letras para la comedia, y loa de Santa Bárbara. La primera es una Pintura en Ecos, sacada por la de la Esposa de los Cantares, que es la siguiente» (p. 441-442). Consiste esta en 36 octosílabos con asonancia en los pares en $e o$, divididos en cuartetas, detrás de cada una de las cuales hay un eco consistente en repetir dos o tres veces una palabra que es parte de la última de la estrofa (por ejemplo: ...desempeño / Empeño, empeño; ...cabellos / Bellos, bellos; ....apremio / Premio, premio, premio; ...desiertos / Ciertos, ciertos, ciertos, nótese el seseo en este caso). 
Después viene un «Laberyntho, que se lee por muchas partes al nombre de Santa Bárbara» (entre pp. 442-443), en una página doble de seis columnas formadas por siete palabras que empiezan por cada una de las letras de BÁRBARA, más un texto latino y explicaciones de las palabras. El modelo de Rengifo parece evidente.

Termina la serie dedicada a Santa Bárbara con "Otra letra» (p. 443) de 20 versos, divididos en cinco cuartetas $(8-a-4 a)$, con la misma asonancia ae en todos los versos pares.

Los «Documentos morales, a un amigo» (p.445-458), que vienen a continuación, son un romance octosílabo en eo de 400 versos divididos en cuartetas.

Sigue un grupo de poemas dedicados a San Agustín bajo el título de «El Apolo africano, y águila de la Iglesia, el grande Augustino, su vida, y milagros, escrita en cien canciones». Empieza con un poema «Al lector. Madrigal» (p. 460-462), que consta de 72 endecasílabos y heptasílabos consonantes al modo de silva.

Continúa con otra silva de 84 endecasílabos y heptasílabos titulada «Explicación del título» (p. 463-465), donde leemos las consonancias copia / propria; necia / Iglesia.

El grueso del conjunto dedicado a S. Agustín es el poema titulado «El Apolo africano» (p. 466-511), compuesto de estrofas que F. Álvarez de Velasco llama canciones, y que en realidad son estancias de 14 versos, endecasílabos y heptasílabos, con el mismo esquema de rima: $A B C A B C c d d E E d F F$. La última de las cien estrofas funciona como remate y tiene 8 versos: $a B a B c C D$ $D$. En total, pues, el poema, con forma de canción italiana, tiene 1394 versos.

Un «Poema panegírico, al Licenciado Don Gabriel Álvarez de Velasco, su padre», y «Dedicado a Juana María de San Estevan, y María de San Gabriel, sus hijas, y hermanas del autor, Religiosas del Convento de Santa Clara, en el muy ilustre de la Ciudad de Santa Fe» (p. 513-521) se compone de un comienzo formado por 34 versos endecasílabos y heptasílabos consonantes a modo de silva, seguido de 24 octavas reales. Cada estrofa va titulada con el nombre de octava y el número correspondiente.

IV. El último conjunto de poemas incluidos en la Rhythmica de Francisco Álvarez de Velasco es el dedicado a Sor Juana Inés de la Cruz, aprobado por Fr. Manuel de la Gándara Cossío en Burgos el 20 de enero de 1703, y titulado Carta laudatoria de la insigne Poetisa la señora Soror Inés Juana de la Cruz, Religiosa del Convento de señor San Gerónimo de la Ciudad de México, Nobilissima Corte de todos los Reynos de la Nueva-España. Empieza con una "Carta que escrivió el autor a la señora Soror Inés Juana de la Cruz», en prosa, fechada el 6 de octubre de 1698 (p. 626-528), seguida de una larga silva de 492 versos (p. 528-542). La composición está llena de referencias al saber literario. Desde el punto de vista de la métrica interesa la mención de Rengifo y de Caramuel (vv. 284-286: Destroçando de Oracio el arte viejo, / El vulgar de Renxifo, y aun el nuevo / Del subtil Caramuel, insigne en todo). Nótese la valoración positiva de Caramuel. 
Sigue la composición "Al mismo assumpto romance endecasílabo de esdrújulos» (p. 543-545), 68 endecasílabos esdrújulos asonantes en aa los pares.

Viene a continuación una serie de composiciones típicamente barrocas. La primera es un laberinto formado por cuatro endecasílabos, repetidos como brazos de una cruz en cuyo centro se lee el nombre de Inés y Nise, «que se lee por todas partes». Los endecasílabos son: Uive ya sin estorvos de la embidia, / Ni hable rabiosa ni se empeñe a verte, / Pues sabe es inpossible al escucharte, / Ni a tu fama elevarse ni atreverse (p. 546).

Sigue "Otro laberinto de otra Cruz al mismo assumpto, en que se forma un copla endecasílaba para abaxo, y otra por los braços; y en el centro de ella, empeçando desde la $M$, se lee por seis partes Musa, y por quatro Sabia, y por una Talia; y quitada la raya que sobre la $A$ forma una $T$, dize Alia, con que sale Alia, Musa, Sabia, Talia» (p. 548-549).

Los sonetos que vienen inmediatamente después se caracterizan también por sus artificios. Así el dedicado «A los dos libros de Soror Inés» (p. 550-551) en el que se forma una redondilla con las primeras palabras de los versos leídas de arriba hacia abajo (Ser otro y ser especial / en el segundo se ve / y assi no se diga que / el primero es sin igual); u otra redondilla con las segundas palabras leídas de abajo hacia arriba (el primero es sin igual / y assi no se diga que / en el segundo se ve / ser otro y ser especial). Las redondillas vienen reproducidas a continuación del soneto ${ }^{15}$.

El segundo es un «Soneto en consonantes agudos» (p. 552), y el tercero «Al segundo tomo de Soror Inés Juana de la Cruz» (p. 553) se ajusta a la forma clásica, aunque consuenan viveza / impressas.

El artificio del cuarto viene explicado en el mismo título: «Otro en esdrújulos, en que empieçan los más pies con los nombres de las Musas, con sus oficios o condiciones» (p. 554), donde consuenan dialéctica / frenética.

Muy interesante es el último, «Al mismo assumpto, y a la silva de la Noche, y del Sueño. Soneto. Paronomático» (p. 555). Paronomático tiene que hacer referencia a la paronomasia de las palabras que riman jugando con formas iguales que se diferencian solo por la vocal tónica: Nise / nace / haze / hize // frise / frase / passe / pise // pese / posse / puse // esse / osse / use. Las cinco vocales diferencian las cinco rimas del soneto, todas terminadas en se (con seseo). Es

15. El seguir distintos recorridos de lectura en un poema es propio de los laberintos, como se ha visto en algún ejemplo del mismo Álvarez de Velasco. Sor Juana Inés llama Labyrinto hendecasyllabo un romance endecasílabo, que se lee de tres maneras: como endecasílabo, como octosílabo (empezando después de la primera raya) y como hexasílabo (empezando por la última raya del verso):

Amante ----- Caro,------ Dulce Esposo mío,
Festivo, y --- Prompto --- Tus felizes años
Alegre ------ Canta ----- Solo mi cariño,
Dichoso, ---- Porque ----- Puede celebrarlos. Etc.

Véanse Segundo volumen de las obras de Soror Juana Inés de la Cruz. Sevilla, Tomás López de Haro, 1692, p. 307-308; Tomás Navarro Tomás, Los poetas en sus versos, op. cit., p. 167. 
un tipo de rima propio de la poesía burlesca usado por Quevedo o Sor Juana Inés, por ejemplo ${ }^{16}$.

Las composiciones dedicadas a Sor Juana continúan con un romance «A las obras, y segundo libro de Soror Inés Juana de la Cruz, y especialmente a la Silva del Sueño» (p. 556-561), formado por 184 octosílabos asonantes en ae divididos en 46 cuartetas.

La composición siguiente está formada por 40 estrofas con el esquema 7 a - $11 \mathrm{~A}$, con la misma rima asonante en $e e$ en todo el poema, y se titula «A la misma señora, endechas endecasílabas» (p. 562-566).

El conjunto de versos termina con la «Segunda carta laudatoria en jocosas Metáphoras, al segundo libro de la sin igual Madre Soror Inés Juana de la Cruz» (p. 567-586), formada por 607 endecasílabos y heptasílabos consonantes en forma de silva. Los versos 492-513 contienen un acróstico (Soror Inés Juana de la $\mathrm{Cruz}$ ), forma métrica que es descrita en los versos inmediatamente anteriores (vv. 480-491).

Termina la obra de Francisco Álvarez de Velasco con unos textos en prosa, donde llamamos la atención sobre la «Advertencia, y protesta del autor, con que da fin este libro» (p. 620), inmediatamente antes del índice de poesías, por la referencia a los americanismos que han observado algunos lectores de la corte y que no ha podido corregir por habérselos señalado una vez impresa la obra.

V. Después de la descripción métrica de los poemas, hay un aspecto que merece ser comentado: la terminología empleada por el mismo autor. Pues es patente la preocupación por la forma métrica en el mismo título o en la introducción a las distintas composiciones, según costumbre de las ediciones de poesía de la época.

\section{Verso: decámetro, eneámetro}

Un primer detalle digno de comentario es la designación ocasional de los versos según su número de sílabas por Juan Caramuel (1665): decámetro, eneámetro son versos que tienen el último acento en la décima y en la novena sílaba, respectivamente, es decir, endecasílabo y decasílabo. El contexto de estos usos en F. Álvarez de Velasco es: «elegías decámetras» (p. 12), «quartetas decámetras» (p. 17), «romance eneámetro» (p. 56). Pero el término «decámetro» no anula el de "endecasílabo", como se ve en ejemplos como: «romance endecasylabo" (p. 219), «romance endecasílabo de esdrújulos» (p. 543). Pie significa verso (p. 56); y truncados, versos agudos (p. 334).

16. José Domínguez Caparrós, «De métrica burlesca», en Ignacio Arellano y Antonio Lorente Medina (eds.), Poesía satírica y burlesca en la Hispanoamérica colonial, Pamplona, Universidad de Navarra, Iberoamericana, Vervuert, 2009, p. 80. 


\section{Cuarteta, redondilla y copla}

En cuanto a las estrofas, emplea el término de quarteta para referirse a la estrofa de versos endecasílabos con rima consonante $A B B A$ (p. 17), que más adelante es designada como redondilla de arte mayor (p. 309). Arte mayor no significa el verso de Juan de Mena, sino el endecasílabo. En una ocasión titula como "coplas» a la parte del villancico constituida por un romance dividido en cuartetas (p. 276); y también llama «coplas» a las 15 cuartetas con el esquema 8 $a^{\prime}-11 A^{\prime}$ (todas con la misma asonancia aguda en $o$ ) que siguen a la intervención de los coros en una «letra para cantar» (p. 407). Parece referirse a cada grupo de cuatro versos con asonancia en los pares con el término de copla. Aparece también el término de "copla endecasílaba", cuando explica dos laberintos en forma de cruz, para referirse a estrofas de cuatro versos endecasílabos. Copla designa también la redondilla $8 a b b a$ (p. 551).

\section{Quintilla y sextilla}

La estrofa de cinco octosílabos con rima consonante ( $a b a a b ; a b a b a$ ) se llama quintilla: «quintillas» (p. 336, 363, 371, 405). Un único ejemplo de lo que llama sextilla responde al esquema de seis octosílabos con rima consonante $a b a b a b$ (p. 298). Los endecasílabos pareados en consonante son llamados disticos (p. 300).

\section{Octava}

El título de "octavas» se aplica al conjunto de estrofas de ocho endecasílabos que consuenan $A B A B A B C C$ (p. 118) o el de «octava» a cada una de ellas (p. 514).

\section{Décima}

Las «dézimas» aparecen tanto en glosas, con el esquema $8 a b b a . a c c d d$ $e+e$ (quebrado) (p. 84, 95); como en el título de un poema en décimas con el esquema de la espinela $8 a b b a . a c d d c$ (p. 389, 428).

\section{Soneto}

El término de soneto aparece siempre que se emplea esta forma, y muy frecuentemente adjetivado de acuerdo con su característica: «soneto acróstico» (p. 60); «soneto en esdrújulos» (p. 321, 326); «soneto en agudos» (p. 413) o «soneto en consonantes agudos» (p. 552); «soneto paronomático» (p. 555). A veces, aunque el soneto esté en consonantes agudos, no se indica esta característica en el título y se llama solo «soneto» (p. 21, 132, 133, 145, 147). 


\section{Romance}

Otro de los términos métricos muy presente en la obra del poeta neogranadino es el de romance, y como en el caso del soneto aparece a veces adjetivado de acuerdo con alguna peculiaridad: «romance eneámetro» (p. 56), «romance endecasylabo» (p. 219), «romance endecasílabo de esdrújulos» (p. 543).

\section{Silva}

Con el término de sylva o silva son tituladas combinaciones de endecasílabos y heptasílabos consonantes sin esquema previo y que tienen entre 30 (p. 258) y 1238 versos (p. 161), con otras de 217, 97, 48, 189, 107 o 133 versos (p. 120, 216, 257, 259, 277, 304). Digno de destacar es el poema titulado «Sermón eneuclástico" por su original combinación de cinco odas pindáricas con el mismo esquema quevedesco (estropha o estrophe, antistrophe, epodo $)^{17}$ seguidas de tres silvas, tituladas "sylva primera» (48 versos), «sylva segunda» (30 versos) $\mathrm{y}$ «sylva tercera» (189 versos).

\section{Madrigal}

La proximidad del madrigal a la silva queda de manifiesto cuando nuestro poeta titula como «madrigal» combinaciones de endecasílabos y heptasílabos que consuenan sin esquema previo y con número de versos que van de los 28 (p. 54) a los 72 (p. 460) pasando por otros de 30 (p. 62) y de 66 (p. 425) ${ }^{18}$. Nótese que en todos los casos sobrepasa la extensión de los 20 versos asignada por Caramuel como máximo al madrigal, y cómo llama «silva» a composiciones que son más cortas, con 30 y 48 versos, según se ha visto.

\section{Canción, canción real, lira}

Un grupo importante de formas en que se combinan endecasílabos y heptasílabos es el relacionado con la canción italiana. La terminología empleada por nuestro autor lleva a pensar que considera canción, canción real o lyra a la estrofa o estancia de que se compone la canción italiana. Así, titula «canciones reales» al conjunto de 20 estrofas con el esquema de endecasílabos y heptasílabos que consuenan según el siguiente esquema $A B C A B C c d d E$ $E D F F$; falta una estrofa final más corta que funcione como remate (p. 150). El larguísimo poema (1394 versos) titulado «El Apolo africano» (p. 466)

17. Caramuel, op. cit., p. 516-532, trae ejemplos de esta clase de poemas en latín e italiano.

18. La extensión de los madrigales de Quevedo se ajustan más a las medidas señaladas por Caramuel, pues la mayoría están entre los 10 y los 19 versos, aunque uno de la Musa VI (p. 205) tiene 29 versos: Tú sola, Cloris mía / Que si miras sin velo. Véase Francisco de Quevedo Villegas, Obras, Tomo III, Poesías, Amberes, Henrico y Cornelio Verdussen, 1699. Accesible en línea: Biblioteca Virtual Miguel de Cervantes. 
consta de 99 estrofas de 14 versos, endecasílabos y heptasílabos, con el mismo esquema de rima: $A B C A B C c d d E E d F F$. La última, la número 100, es más corta, como suele ser el remate de la canción italiana, y tiene 8 versos: $a B$ $a B c C D D$. Cada una de las cien estrofas va precedida del título de "canción» y el número correspondiente. Más próxima a la forma canónica de la canción italiana es la composición titulada «lyras», con cuatro estrofas de heptasílabos y endecasílabos consonantes según el esquema a $b A B C D$ c d E EFFGGH $H$; y un remate de cuatro versos, $A$ a $B B$, en que el poeta, como es tradicional, se dirige a la canción.

\section{Ovillejo. Verso suelto}

La combinación de endecasílabos y heptasílabos consonantes con abundancia de pareados es calificada por nuestro autor como «ovillejos» (p. 333). Otra forma característica del endecasílabo como la del verso suelto, sin rima, no es empleada, aunque es nombrada en la advertencia a las Elegías decámetras para referirse a una traducción de José de Valdivieso (p. 18-19).

\section{Endecha}

Una combinación de heptasílabos y endecasílabos con esquema bien definido es la de la endecha real ( $7-a-11 A$, con rima asonante). Nuestro autor emplea este esquema en un poema donde el estribillo inicial va seguido de un grupo de 13 estrofas con esta forma que titula «endechas» (p. 289), añadiendo tras cada grupo de cuatro versos a modo de estribillo un mismo verso repetido que asuena con ellos. La asonancia es la misma en toda la composición, como una clase de romance. El mismo esquema, sin el verso repetido como estribillo, es calificado de "endechas endecasílabas», con la misma asonancia en ee en los versos pares de toda la composición, de 160 versos (p. 562). Hay otras ocasiones en que emplea esta estrofa pero no da ninguna indicación sobre la misma, como en la "Glossa, o troba del Laudate pueri Dominum» (p. 286), con adición del verso a modo de estribillo tras cada cuatro versos; o en las 16 estrofas que siguen a la primera, repetida como estribillo en diversos lugares, del poema «Reconvenciones tiernas...» (p. 430).

\section{Estribillo}

Hay una serie de términos que están entre lo que es un concepto genérico y lo que es una forma métrica. Se trata de formas que no se identifican con un esquema métrico preciso, aunque se refieren a tipos de poemas o de estructuras ligadas a un género, como, por ejemplo: estribillo, villancico, glosa.

$\mathrm{El}$ «estrivillo» puede consistir en: 16 versos irregulares esdrújulos que preceden a 7 cuartetas (p. 72); 8 versos irregulares, con mezcla de rima consonante y asonante que precede a 13 «endechas» (p. 289); un pareado octosílabo asonante 
que se repite tras cada cuatro versos de un romance (p. 294); una especie de introducción en prosa que precede a la parte en verso (calificada de «metro») en una letra (p. 410).

\section{Villancico}

El «villancico», poema que se canta, tiene formas variadas que incluyen la irregularidad de todos sus versos (p. 273), o de parte de ellos (11 versos iniciales) que siguen con formas regulares arromanzadas (p. 276); un cuerpo central de seis cuartetas arromanzadas en $e o$, precedidas y seguidas de versos irregulares (de 8; 5 y 7; 10 y 6; 12 y 6 sílabas) asonantes también en $e o$ (p. 353). Alguna de las composiciones que titula «letra para cantar» está próxima de estas formas del villancico (p. 407). Este carácter del villancico, hasta cierto punto indefinido o que admite las más variadas formas, es descrito claramente en el título de la composición «Al Nacimiento de Christo Villancico, y Ensalada, que es un género de versos, y composición, que no va atado a precisos consonantes» (p. 356). Es decir, un villancico puede ser también una «ensalada», forma definida por Rengifo (cap. LXVI) como mezcla de todas las diferencias de metros, aun de otras lenguas, sin orden de unos a otros, al albedrío del poeta, y con variedad en la música también.

\section{Glosa}

La "glosa" puede adoptar distintas formas y no es raro que haya una indicación sobre la nota métrica que la caracteriza, como el uso de la décima (p. 84, 95); la "glossa en esdrújulos» (p. 302), en espinelas esdrújulas, o la "glossa de truncados», es decir, en versos agudos, también en espinelas (p. 334). La glosa se identifica una vez con la «troba» (p. 286). En esta ocasión se emplea una forma distinta de la décima: la endecha real. La descripción del Diccionario de Autoridades (1726-1739) nos proporciona la base de dicha asimilación cuando define trova como «la composición métrica formada a imitación de otra, siguiendo el méthodo, estilo, u consonancia, o parificando alguna historia, o fábula».

\section{Idilio. Himno}

Más alejados de un sentido métrico están los términos de «Idilios» (p. 102: silva de 478 versos; término empleado por Quevedo para el título de algunas de sus poesías, según nos informa el Diccionario de Autoridades, pero no asociado a una forma estrófica determinada ${ }^{19}$ ); «hymno» (p. 198: silva de 589 versos); o «ilidion» (p. 283: silva de 88 versos). Todos son términos para formas poéticas que usan la silva.

19. En la Musa IV de Quevedo los poemas titulados Idylio tienen las siguientes formas estróficas, en versos de 7 y 11 sílabas: $a B a B C C, A B B A$, AbABCC, $A B A B C C$, Silva. 


\section{Acróstico}

Un último grupo de términos se refieren a las formas artificiosas recogidas en tratados como los de Rengifo o Caramuel. Nuestro autor emplea el término de «acróstico» para calificar un soneto de ese tipo (p. 60) y en un pasaje del largo poema de 607 versos, dedicado a Sor Juana Inés (p. 567). En los versos 480-491 de esta composición se define el acróstico en los siguientes términos:

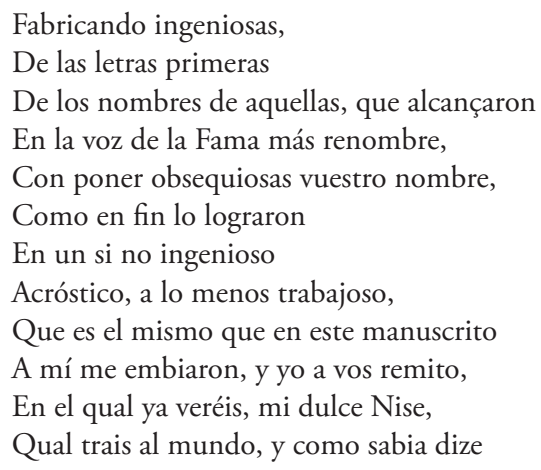

y los versos siguientes contienen el acróstico formado con la primera letra de cada uno de ellos: Soror Inés Juana de la Cruz. Para F. Álvarez de Velasco lo trabajoso, lo dificultoso de la composición la justifican.

\section{Laberinto}

Otros ejemplos de este aprecio de la dificultad, de los que el autor se mostraba orgulloso en el prólogo, son: el «laberyntho» a Santa Bárbara con texto de cinco versos latinos (entre p. 442-3); o el que dedica «Al último nombre de Soror Inés Juana de la Cruz, laberinto, en que se lee la copla endecasílaba, que se verá por los medios de la Cruz; y en el medio de ella, el nombre de Inés, y Nise, que se lee por todas partes» (p. 546), seguido de las instrucciones para su lectura; y el que le sigue, también en forma de cruz: «Otro laberinto de otra Cruz al mismo assumpto, en que se forma una copla endecasílaba para abaxo, y otra por los braços...» (p. 548).

\section{Eco}

El ejemplo de «Pintura de Ecos» (p. 441) entra también en este grupo de composiciones artificiosas, aunque no es una forma muy complicada de eco.

\section{Lista de términos métricos}

La lista de los términos métricos presentes en la obra de Francisco Álvarez de Velasco incluiría los siguientes: 


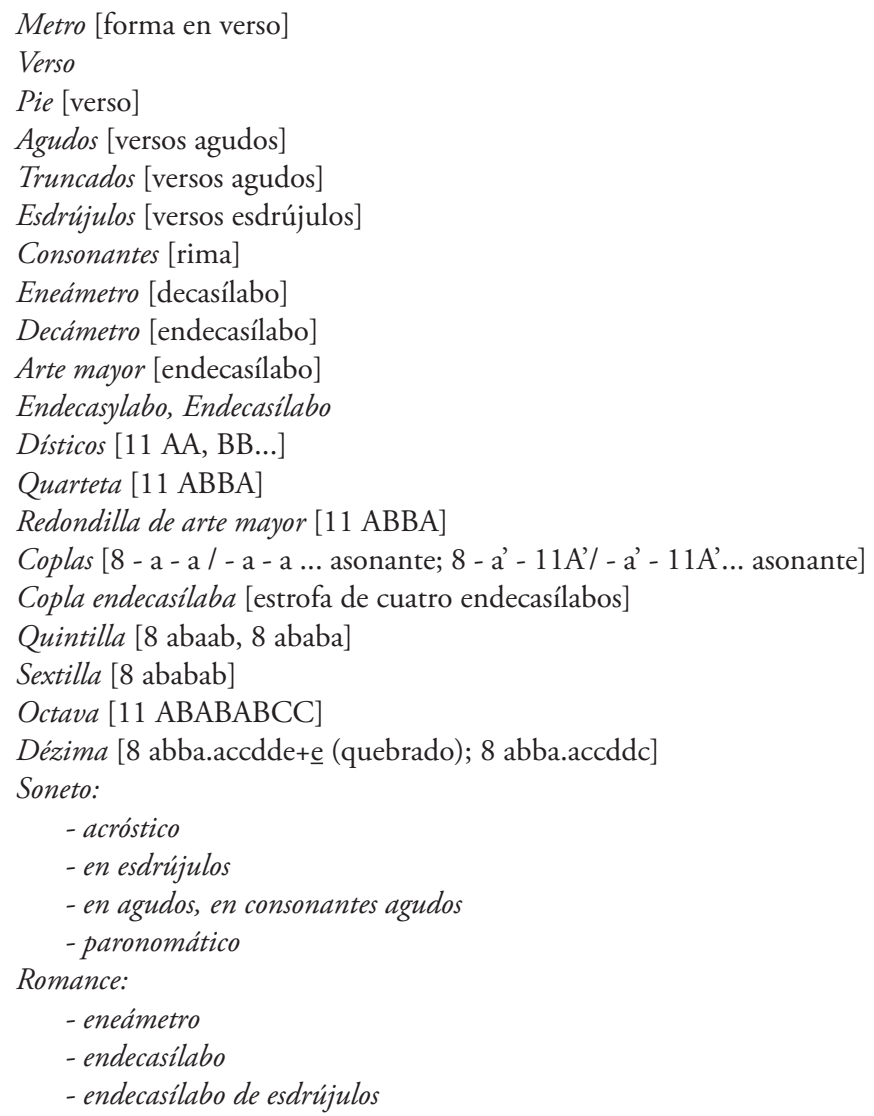


VI. La obra de Francisco Álvarez de Velasco representa de forma típica el saber métrico de un poeta normal de su época. Puede ilustrarse este aspecto de su quehacer a la vista de los tratados de métrica conocidos por nuestro autor -el de Rengifo y el de Caramuel- y de otra importante fuente de terminología métrica próxima a la fecha de la publicación de su obra, la edición ampliada de Rengifo en el siglo XVIII por Joseph Vicens (1703), reeditada hasta 1759. Esta última obra actualiza la terminología métrica a la vista de la producción poética contemporánea, con atención especial a la Lyra poética de Vicente Sánchez (Zaragoza, Manuel Román, 1688), y a las Nenias reales que la barcelonesa Academia de los Desconfiados dedica en 1701 al rey Carlos II después de su muerte $^{20}$. Tiene que quedar para otra ocasión el comentario de los detalles que resultan de la comparación del saber métrico de Francisco Álvarez de Velasco con el de estas obras ${ }^{21}$, tanto tratados teóricos como de creación, con vistas a ir dibujando un cuadro de la métrica del final del barroco. Época que, repetimos, preludia detalles de por dónde se va a producir la renovación del verso moderno español a partir del siglo XVIII.

20. El título completo de esta obra es: Nenias reales y lágrimas obsequiosas que a la inmortal memoria del gran Carlos Segundo rey de las Españas, y emperador de la América, en crédito de su más imponderable dolor, y desempeño de su mayor fineza, dedica y consagra la Academia de los Desconfiados de Barcelona. Las saca en su nombre a la luz pública Don Ioseph Amat de Planella y Despalau. Barcelona, por Rafael Figueró Impressor, año 1701. Hay referencias a otras obras y autores en las adiciones de Vicens, como son Maravillas del Parnaso, recopilación de Jorge Pinto de Morales, Lisboa, 1637; o Ledesma, Góngora, Sor Juana Inés de la Cruz. Hay edición moderna de Vicente Sánchez, Lira poética, edición de Jesús Duce García, Zaragoza, Prensas Universitarias de Zaragoza, 2003, 2 vols.

21. A los títulos mencionados, añádanse los de ediciones de finales del siglo XVII de la poesía de Sor Juana Inés, como Inundación Castálida, Madrid, 1689; Segundo Volumen de las obras de Soror Juana Inés de la Cruz, Sevilla, 1692; y Fama y obras póstumas, Madrid, 1700. 
